\title{
An Eco-Translatology Approach to the English Translation of Chinese Internet Catchwords
}

\author{
Fang Wang \\ College of Foreign Languages, Changchun University of Science and Technology, Changchun, China \\ Email: harmonywang@163.com
}

Received 18 August 2014; revised 5 October 2014; accepted 18 October 2014

Copyright (C) 2014 by author and Scientific Research Publishing Inc.

This work is licensed under the Creative Commons Attribution International License (CC BY).

http://creativecommons.org/licenses/by/4.0/

(c) (i) Open Access

\begin{abstract}
In this article, qualitative analysis is adopted. Data of internet catchwords are chosen from those popular in recent five years. The thesis aims at throwing lights on further studies of the English translation of Chinese internet catchwords and promoting the worldwide transmission of Chinese internet catchwords and internet culture. It is hoped that the dissertation could provide a new perspective for the study of internet catchwords.
\end{abstract}

\section{Keywords}

\section{Internet Catchword, Eco-Translatology, Adaptation, Selection, Translation}

\section{Literature Review}

In this part, internet catchwords will be firstly discussed. Then, previous studies at home and abroad will be reviewed and their limitations will be revealed.

\subsection{Internet Catchwords}

With the popularization of the internet, internet catchwords, a new form of language, are drawing increasing academic attentions. With its vivid and brief form, internet catchwords become extremely popular. In this section, the definition and features of internet catchwords will be introduced with Chinese examples.

\subsubsection{Definition of Internet Catchwords}

Internet language arises with the emergence and development of internet media. Chinese internet language ap- 
peared after China joined international internet on April 20th 1994. Foreign scholars define internet language differently, among whom the most representative one is David Crystal [1].

However, in China there is no clear definition on internet language until now. Different scholars hold different points. In this dissertation, two representative definitions are as follows:

1) Internet language is referred to computer language at first. Nowadays it also includes the language used on the internet.

2) Internet language refers to the language used on the internet and languages related to the computer which consists of images, signals, words and conversations in chat rooms and BBS [2].

The first one is a rather broad definition without specific explanations. In the second definition, the components of internet language are illustrated but no clear classification is given. In fact, internet language can be classified into three categories, computer programming language, web terms and language used in chat rooms and BBS. In its narrow sense, internet language refers to the third which is also the research object of the thesis. Actually, the internet catchword is a kind of new language form which is popular and may last for a short period.

Created by netizens, they are words or sentences derived from hot events and have specific meanings. After accepted by people, their pragmatic scope is enlarged and widely used in newspapers, magazines, the internet and TV shows. Although their number is relatively small, the influence can't be ignored. Statistics from the China Internet Network Information Center (CNNIC) show that at the end of December, 2012, the number of Chinese netizens has reached 564 million, of which the penetration rate of is $42.1 \%$, which indicates that once formed, internet catchwords can be transmitted immediately.

\subsubsection{Linguistic Features of Internet Catchwords}

Internet catchwords are created to meet people's social and communicative needs on the internet. Being part of internet language and rooted in particular social backgrounds, internet catchwords have their own peculiar features. In the following sections, a brief introduction of the linguistic features of Chinese internet catchwords will be explored.

\section{1) Phonetic Features}

Different from other kinds of language, internet language is often used, especially for the purpose of bringing people closer or activating the atmosphere. With its special phonetic features, it is extremely popular among netizens.

Phonetically, internet language can be discussed from the following three aspects: onomatopoetic word, homophones and reduplicating.

a) Onomatopoetic words

Onomatopoetic words refer to the words created by imitating sounds of nature. Frequently adopted by netizens due to its vivid expression and brief form, onomatopoetic words in Chinese internet catchwords comprise mainly of Chinese characters, Arabic numerals and Chinese pinyin. Typical examples are: "heihei", "xixi”, "huhu”, "hah", “555", "hehe”, "xixi”. Seeing or hearing them, people can immediately understand what was transmitted. Besides, onomatopoetic words can not only pull people together, narrow the distance between them but also help enliven the rigid atmosphere of internet chatting.

b) Homophones

Possessing a large number of internet language, homophones refer to the words that have the same pronunciation with others but different characters and meanings. It mainly consists of derivation from English, Chinese characters, Arabic numbers and also combination of both English and Chinese. For instance, "fensi" is the transliteration of English word "fans"; "xijv" is used to represent "comedy" meaning "comedy" in English. "1314" means "forever" in Chinese because it has similar pronunciation with "in all one’s life". Since numbers are easily typed, the combination of Arabic numbers is extremely popular.

c) Reduplicating

Reduplicating here means the repetition of words or sentences. Nowadays, more and more people prefer to adopt repeated words to convey particular intentions. For example, "dongdong” which abandons the character "xi" and repeats the first character refers to "things" in English so as to show the lovely personality or shorten the communication distance and bring them closer. Another instance is "piaopiao" adopting the same way to deal with the original phrase means "beautiful" or "gorgeous" in English. Similar examples are "baobao", "fanfan", etc. 


\section{2) Lexical Features}

Lexicology, in its technical sense, deals with the analysis and creation of words, idioms and collocations. Internet catchwords have their particular lexical features which will be studied from three aspects: Acronym, Arabic numbers and newly created words.

a) Acronym

Acronym refers to those words formed by combining the first character of each word. In Chinese internet catchwords, acronym can be roughly classified into two kinds: Chinese acronym and English acronym. For example, "GG" is the acronym of Chinese phrase "brother", "BF"/"GF" are the abbreviation of "boyfriend" "girlfriend", "DIY" is the acronym of "do it yourself", Due to its brevity, some of them even replace original words and are widely adopted by netizens.

b) Arabic numbers

In Chinese, some Arabic numbers have similar pronunciation with Chinese characters and can be easily associated with them. Typical examples are: "520" with similar pronunciation of "I love you." in Chinese means "I love you" in English. For this reason many young people celebrate their love on May 20th every year. Another example is "9494" which has similar pronunciation of Chinese character "yes, yes" means "that is it" in English. Because of its brevity, netizens prefer to adopt Arabic numbers instead of Chinese characters, which has become a trend on the internet.

c) Newly created words

With the society and economy development, newly created words have become a trend in the use of internet catchwords. Due to the influence of some big events, some new words and expressions come into being. For example, in order to communicate more convenient, "weibo" come into our lives which means "micro blog" in English where people can share and get information with limited words. Another instance is "donkey friends" which refers to those people who love outdoor sports and advocate independent travel.

\section{3) Semantic Features}

Semantic studies how meaning is coded in a language. Semantic change plays an important role in increasing the vocabulary of a language. Internet catchword has its own semantic features which will be discussed from the following three aspects: broadening, narrowing and new words with new meaning.

a) Broadening

Broadening refers to the process to extend or elevate the meaning from its originally specific sense to a relatively general one. Most of internet catchwords are borrowed or created in the light of the original ones, whose meaning has been broadened. For example, "it's none of someone's business" once meant "buy soy sauce", nowadays refers to "I just passed by and it has nothing to do with me". "criticize or challenge" whose original meaning is "throw a brick at somebody" means "criticizing somebody's opinions" in internet catchwords.

b) Narrowing

Being contrary to broadening, narrowing means that the original meaning of a word can be narrowed or restricted to a specific sense. "awesome" once was dialect of Fujian Province whose pronunciation is [kik-làt] and meant "exert all one’s strength". During the World Cup of 2010, "awesome" became a popular expression. It can be translated into different meanings according to the context. Because of popularity, it has replaced the original meaning and is known by more and more people with its new implication.

\subsubsection{Cultural Features of Internet Catchwords}

A language, the carrier of culture, embodies a nation's history, cultural background, thinking pattern, values, and social customs and so on. Stemming from the particular internet environment, the Chinese internet catchwords, with humor, novelty and vigor, are closely connected with Chinese culture, in which social customs and values are vividly expressed. In the following, the cultural factors of internet catchwords are discussed with examples.

For example, "diors" is an irony of current Chinese social situation caused by economic imbalance. It refers to man/woman who is poor, short, ugly, generally has dreams and ideals but is too passive to pursue them. Due to close connection with the social background, internet catchword, a new form of language, transmits particular culture of given language.

\subsubsection{Communicative Features of Internet Catchwords}

Any information without communication is useless. Language is a way of transferring people's emotions and opinions. So do internet catchwords. Communicatively, the features of internet catchwords can be roughly dis- 
cussed from three aspects: function, form and effect. Internet catchword, with greater popularity among people, is stronger in communication than other language. Then, different from traditional communication form, the form of internet catchwords is often concise and clear. In communication effect, internet catchwords can convey the intention more vividly.

Typical examples are "beans play with you", "garlic power" which come into being as a result of people's dissatisfaction with rising price of some commodity in China. Another instance is "it's none of your business" which emphasizes the people's indifferent attitudes towards events that are none of one's business. The adoption of these catchwords can convey people's intention more explicitly.

\subsection{Previous Studies on Internet Catchwords and Their Limitations}

Though the internet language has a short history, it has attracted scholaristic attentions at home and abroad. Various angles of studies have been conducted including linguistics, culture, communication, and so on. A comprehensive review of previous studies is requisite.

\subsubsection{Studies of Internet Catchwords at Home and Abroad}

The foreign researches on internet language and internet catchwords began earlier than China. In 1997 the first seminar on "the Internet and language" was held by World Language Center of Research and Information of Hartford University. Some famous international linguists attended the meeting and argued issues on internet language.

Dissertations and reviews on the internet language were frequently published on Language and ELT Journal these years. David Crystal, a famous linguist and leading figure in the study of internet language, published a book named Language and the Internet in 2001 which went through second edition in 2006. It's obvious that this book is a landmark among the studies on internet and internet language. It covers linguistic perspectives on internet language, the medium of netspeak, and researches on four kinds of netspeak including e-mail, chat groups, virtual words and the web. At the end, David looks forward to the linguistic future of the internet.

With the development of technology, the internet is applied into nearly all aspects of our lives. Some new words related to the internet are created. Along with the popularization of internet language and catchwords, the researches are combined with other social science areas, such as sociology, psychology, journalism, communication and semiotics. Theories of other disciplines are adopted to the analysis of internet language and catchwords. For instance, from the angle of culture, the studies of internet catchwords analyze the social functions; the studies emphasize the individual psychological needs from psychological aspects; from education point of view, the values of students are researched and how to guide students to apply internet language and catchwords properly is argued.

In a word, the study of internet catchwords can be roughly classified into two aspects: the pure linguistic studies and the combination of internet language and other disciplines. Both are still at the beginning stage and some uncertainties and shortcomings exist.

\subsubsection{Their Limitations}

The internet language and catchwords have appeared more than ten years which have been drawing increasing academic attentions. More than ten books and hundreds of papers are published. However, three main aspects of limitations still exist. One is the research object that is internet language and catchwords. Most current studies focus on analysis of certain internet catchwords. Some pay attention to the collection of internet language as a whole. Systematical theoretical researches on internet language and catchwords are few in number. Another issue is the research method.

Among the present researches, most periodicals, short of scientific theory guidance, are merely summarization of other studies or a description from one's intuition or experience. The last limitation is few researches in the aspect of eco-translatology, especially the study of English translation under the guidance of eco-translatology have been conducted.

\subsection{The Aim of the Study}

With the economic globalization and political multi-diversification, communication occurs frequently among countries all over the world. Among them, cultural exchange occupies an important position. Cultural commu- 
nication is not only the bridge that connects foreign countries and China, but also the inner demand to promote the globalization and diversity of culture. Global culture communication brings people closer and pushes global harmony forward. With the popularization of the internet and the increasing number of Chinese netizens, internet culture, a fresh culture, is on the rise. The internet is even named as the fourth media in China. Being part of internet language and internet culture, the emergence and development of internet catchwords have been drawing increasing academic attentions at home and abroad.

With the rapid development, researches related to internet catchwords are emerging in an endless stream, most of which mainly focus on the following aspects: linguistic features of internet catchwords, culture analysis, transmission system, instruction meaning and the influence of it on traditional values. However, the current tudies of English translation of Chinese internet catchwords are still scattered. Take CNKI for example, most researches focus the English translation of one or several Chinese internet catchwords. Few structural and systematic researches have been done. Along with the increasing position of China in the world and more frequent communications with foreign countries, more and more foreigners are interested in knowing and getting familiar with China. Therefore, it is urgent and significant for the study of English translation of Chinese internet catchwords.

Translation is not only simple language transformations, but also communication of two kinds of culture. Translator, the subject in the translation process, plays a significant role in language and culture transformation. Professor Hu Gengshen considers that translation process could be described as: a combination of translators' adaptation to translational eco-environment in the name of source text and translators' selection of translations in terms of translational eco-environment [3]. The study of the dissertation should be conducted from adaptation and selection focusing on the following three dimensions: language, culture and communication.

\section{Theoretical Foundation and Methodology}

Owing to unique features of internet catchwords, Eco-translatology of Hu Gengshen is chosen as theoretical foundation for further analysis. In this chapter, the key notions and basic principles of eco-translatology will be briefly introduced and the methodology adopted in this dissertation will be presented.

\subsection{Eco-Translatology}

Based on Darwin's evolution theory, eco-translatology was proposed by Professor Hu Gengshen in recent years. From 2001 until now, many papers and articles related to eco-translatology have been published. An Approach to Translation as Adaptation and Selection, the predecessor of eco-translatology, was published in 2004 which presents the eco-translatogy comprehensively, including research background, philosophical foundation, translator-centeredness, translation process and translation method. Eco-translatology is an ecological approach to translation studies or translation studies from an ecological perspective which can be interpreted as the study of translation by adopting ecological concepts. Although it is a newly born theory, it has been drawing increasing academic attentions and has been widely applied into the analysis of translation activities. The key notions and basic principles of eco-translatology will be illustrated in the following.

\subsubsection{The Real World Goal Perspective}

Study of translation from the perspective of "adaptation", "selection", "survival” and "elimination" is a new attempt in translation studies. These concepts are adopted by referring to Darwin's "survival of the fittest". As the philosophical foundation of eco-translatology, it is a necessary to have a general view of it.

Translation can be seen as the transition of different languages. In his article, Hu Gengshen believes "There is agreement that translation is a language activity, that language is an activity as part of culture, that culture is a result of human activity, and that human activity is part of the natural world."

Darwin's evolution theory is composed of three parts: mutation, adaptation and evolution. Professor Hu borrowed the adaptation theory, which means that the adaptation of organism to environment and the selection of environment for organism, as the theoretical foundation of eco-translatology. In translation activity, the translator has to first adapt to the translational eco-environment and then selects the optimal translation.

\subsubsection{Key Notions of Eco-Translatology}

Eco-translatology was proposed by Hu Gengshen on the basis of Approach to Translation as Adaptation and Se- 
lection. Under the guidance of Darwin’s “adaptation and selection”, eco-translatology probes into the relation, feature and regular pattern of translator's adaptation and selection. Besides, the essence, translation process, evaluation criteria, the translation principle and the translation method are presented and interpreted from the perspective of adaptation and selection. Professor Hu believes translation is a sustainable selection by adapting to translational eco-environment. The theory can be interpreted from four main aspects: 1) translation processcycling process of translator's adaptation and selection; 2) translation principle-multi-dimensional selective adaptation and adaptive selection; 3) translation method - three-dimensional transformations (linguistic, cultural and communicative dimensions); 4) evaluation criterion-multi-dimensional transformations, readers’ feedback and translators' quality [3].

\section{1) Translational Eco-environment}

Translational eco-environment was first put forward by Hu Gengshen in Approach to Translation as Adaptation and Selection in 2004. Professor Hu thinks there are two reasons for the adoption of translational eco-environment instead of context. One is translational eco-environment can match with "adaptation/selection" of Darwin's Evolution Theory. The other cause is the concept, scope and signified of translational eco-environment differ from context. Context refers to language environment.

Translational eco-environment means a world composed of original text, original language and target language. Therefore, the concept of translational eco-environment is broader than the other. Translational eco-environment is an interrelated whole that consists of language, communication, society, the author, the reader and the client. Professor Hu says that the translational eco-environment is a combination of components that influence the translator's optimal adaptation and selection which matters the quality of translation.

As a proverb goes, "no context no text.” Translational eco-environment, a core concept of eco-translatology, deserves more attentions.

\section{2) Translator-centeredness}

One of the essential issues of translation theory is the description and interpretation of translators' role in translation process. The position of translators in translation process has been an eternal subject in translation.

Different from the source text center theory and the translation center theory, Hu Gengshen proposed translator-centeredness which can be regarded as a balance or deconstruction of previous theories. Translator-centeredness which breaks the two extremes of the source text center theory and the translation center theory aims to form an overall balance of translation study. Professor Wang Ning [4] points out that eco-translatology is a theoretical innovation and to some extent contributes to the deconstruction of traditional translation theories.

Although translator-centeredness focuses on the translator's determined role, it is completely different from ecology's anthropocentrism. Anthropocentrism evaluates everything in the light of human's benefits and only human is the subject who values everything. The contents cover: a) In the value system of nature and human, only human is the subject and nature is the object. It's human who masters the value system; b) In the ethical relationship of nature and human, human is the purpose of doing anything; c) All human's activities are to fulfill the need of survival and development. Anything deviating from the above purpose is nonsense; d) Ecology's anthropocentrism was proposed against a background of contemporary ecological crisis in order to reconfirm human's status in the universe. The core viewpoint is to put human's status over the nature.

It's obvious that translator-centeredness and anthropocentrism are completely different concepts. Mixing up the two notions is totally wrong. Professor Hu Gengshen believes that translator-centeredness should be defined as follows: the translator should first adapt to the translational eco-environment and then selects the translation in terms of translational eco-environment. In other words, translator-centeredness means translators' adaptive selection and selective adaptation. Both adaptation and selection should be judged and decided by the translator. Translator undertakes the responsibility in the whole translation process.

\section{3) Translation Process: Adaptation and Selection}

In translation process, adaptation, selection, reservation and elimination are inevitable. Choices should be made in the light of corresponding situations. Actually, the concept of adaptation and selection was not firstly proposed by Professor Hu Gengshen.

The dotted lines around "source text" and "translator" indicate the "translational eco-environment". In the first stage, the source text has pride of place as it "selects" the translator. But this reversible selection could also be regarded as the translator's adaptation to the source text. In the second stage, the translator is the central figure as he or she "selects" and makes decisions about the form of the final target text. In other words, the translator is an actor in the eco-environment by carrying out selection leading to the production of a translation. 


\section{4) Translation Method: Three-dimensional Transformations}

Before the presentation of translation methods, it's necessary to get knowledge of translation principle which can be compared to a macroscopic guidance compared with translation methods. Translation principle is not only an expression of translation theory but also a reflection of translation essence. Eco-translatology is defined as “translator's selective activities after the adaptation to translational eco-environment". Seen from the definition given by Hu Gengshen, the translator also has to make various selections on the basis of adaptation to translational eco-environment which is adaptive selection. Therefore, the translation principle could be summed up "multi-dimensional adaptation and adaptive selection".

In cultural transformation, the culture of target language always affects the translator's thinking and language selections in disparate degrees. Edward T. Hall [5] once said that "Any aspect of human life could hardly get clear of cultural influences and changes". Since differences exist between original language culture and target language culture, the translator should pay more attention to the entire culture system belonging to the original and the target. The transmission of cultural connotation is a significant element judging the translation. Any translation ignoring culture background could hardly arouse the reader's resonances. Hence, cultural transformation indicates the translator should bear cultural consciousness and overcomes cultural discrepancy in order to achieve a successful communication.

\section{Eco-Translatology in the English Translation of Chinese Internet Catchwords}

Under the guidance of eco-translatology, the English translation of Chinese internet catchwords will be discussed in this chapter. In the first section, the translational eco-environment of internet catchwords will be made. Then, the translator's adaptation will be illustrated in the light of needs and eco-environment. Subsequently, translator's selection of the optimal translation will be elaborated in terms of the eco-environment and translator's adaptation. In the final part of this part, some possible translation methods will be proposed in order to have a better transmission of Chinese internet catchwords and internet culture.

\subsection{Eco-Environment of Internet Catchwords}

The translational eco-environment refers to an interrelated whole that is composed of language, communication, society, author, reader and client. Before the conduction of analysis, it is essential to hold a clear and comprehensive view of the eco-environment of internet catchwords of which the main components will be illustrated one by one.

Born in particular environment - the internet, internet catchword, a new form of language, has its linguistic features including phonetic, lexical and semantic features which have been presented in chapter one. Typical examples are "beijv", "xijv", "weibo", "gelivable”, etc. Due to their unique language form and vivid expressions, a general view of language characteristics is necessary in translation process.

Besides, the author should also be taken into account in translation process. The adoption of internet catchwords is to express the author's intentions such as excitement, discontentment, anger, sadness, humor and anxiety. In translation process, attentions should be paid to the delivery of the author's intentions. Any translation that ignores the author is unwise.

At last but not in the least, the reader is also an element deserving attentions. Readers' response has always been one of the criteria judging the quality of the translation, which occupies an important position in translation area. Plenty of researches have been conducted of readers. Professor Hu Gengshen also believes that the reader is a necessary element judging the translation quality in which readers' recognition, social environment, thinking patterns, education background, etc. are included.

Above are the main factors of eco-environment which should be regarded as the measurement to choose an optimal translation. In the translation process, the translator should first adapt to the eco-environment of internet catchwords, get familiar with all the elements and bear them in mind in the whole translation process.

\subsection{Translator's Adaptation}

Professor Hu Gengshen believes that translation is a combination of translator's adaptation and selection. Adaptation, a main part of eco-translatology, is an unavoidable stage in translation process. According to $\mathrm{Hu}$, the translator must first adapt to the eco-environment of internet catchwords, personal needs and ability. However, 
the translator's ability is an invariant and can not be improved in short time. Therefore, stress will be put on translator's need and eco-environment of internet catchwords. Only after the adaptation, the translator can have a comprehensive recognition of internet catchwords. Two parts will be included in this part: translator's adaptation to needs and adaptation to eco-environment.

\section{Translator's Adaptation to Needs}

In eco-translatology, the need mainly refers to the translator's needs, among which the realization of survival need and personal values, the inner motivation and goal of the translator are the most basic and important ones.

An typical examples is "geilivable” which is extremely popular among people and is extensively applied in newspapers, TV shows and the internet. Translator and amateurs who are interested in this phrase try to translate it into English. Many corresponding English versions emerge including "powerful”, "fantastic”, "wonderful”, "cool”, "gelivable" which is a new word created by netizens in terms of the English morphology. The choice for the optimal translation depends on the eco-environment of this catchword. Usually curiosity or interest is one of the reasons pushing the conduction of a translation activity. After the realization of the basic need, translator will continue to pursue superior needs until the realization of psychological needs and self-value. In the translation process, the survival, development and self-realization needs have been driving the translator pursue an optimal translation.

In a word, the translator will experience needs' transition in the translation process. The aim of this section is to interpret the inner minds of translators and make the reader get a basic knowledge. Although the center of eco-translatology is translator-centeredness, the translator has to go through a following process: adapt to the needs and eco-environment, improve the adaptation ability, optimize multi-dimensional adaptation and selection and pursue more superior degree of holistic adaptation and selection. With great importance in the translation process, adaptation means better acquaintance with the source and original text which is the first and most basic step for conducting translation. Therefore, the translator should make fully comprehensive preparations at the adaptation stage and improve their abilities and knowledge in order to achieve a better translation.

\subsection{Translator's Selection}

In eco-translatology, Professor Hu believes that translation is a continuous adaptation and selection by referring to multi-dimensional transformations which mainly are linguistic, cultural and communicative dimensions. Translation process is a cyclical alternation of selective adaptation and adaptive selection. Therefore, this part will emphasize the analysis of translator's selection in terms of each dimension with internet catchwords selected from 2008 to 2012. Some explanations or notes will be presented to illustrate which translation is better. However, analysis in each dimension is not absolutely separated from another two. Actually, there is no clear boundary among the three. Examples used in this dimension could also be applied into other discussions. The only distinction is the different focus of each dimension. It's inevitable that some examples will appear more than one time.

\subsection{Possible Translation Methods}

In the last two sections, with the eco-environment of internet catchwords, the translator's adaptation and selection are explored from three dimensions: language, culture and communication. Besides, some Chinese internet catchwords and corresponding English translations are presented to demonstrate the analysis. In eco-translatology, under the guidance of multi-dimensional adaptation and adaptive selection, Professor Hu [6] proposes a translation method that is three-dimensional transformations focusing on linguistic, cultural and communicative dimensions. However, Hu's method is a macroscopical one guiding translation process on the whole. The translator should make his or her own choices of different methods and skills by combining the characteristics of internet catchwords and the original and target language. No matter what kind of method is chosen, the English translation must be a reflection of three-dimensional transformations.

\subsubsection{Literal Translation}

Literal translation means that the translation not only keeps the content of the original text but also retains the form of the original one. It is often used in the translation of internet catchwords that bear lesser culture and social factors and are not extremely strange for foreigners. For example, "weibo" which is a popular communica- 
tion tool in recent years. Featured as short messages, it is a minimized version of blog. In foreign countries, face book and twitter, sharing some similarities with Chinese blog, are extremely popular among people. Due to the common cognition of this kind of communication tool, it is easier for foreigners to understand the English translation of "weibo"- "micro-blog". Another example is "tuangou". Unlike purchasing one by one, "tuangou" means many people buy the same commodity in a fixed time. Because of greater purchasing power, they can enjoy a lower price. Since this catchword is easily understood, literal translation-"group purchase" is adopted. Other similar instances are in the following: "zhainan"_-indoorsy man”; "zhainv"—-indoorsy woman"; "leiren"-_"shocking”; "Jiangnan style"- "Gangnam Style”. Since these internet catchwords have been analyzed in previous parts, further discussions will be omitted.

To sum up, for those Chinese internet catchwords that share the similar cognition and social backgrounds with the target language, literal translation is a better method for its concise and exact expression.

\subsubsection{Literal Translation with Explanation}

For some internet catchwords, free translation will misinterpret the implication of the original text and literal translation will make the foreigners confused due to the deficiency of related cultural and social backgrounds. Hence, literal translation with an explanation or annotation is a better way to deliver the connotation. An typical example is "fenghuangnan" which is used to describe this kind of men: Born and grew up in the country, they struggle to leave the village and finally live in the city with his efforts. Phoenix refers to the king of all birds in China's myth story which also exists in western fairy tales named immortal birds. Phoenix is an image of immortal, firm and persistent characteristics in western culture which can vividly transmit the connotation of above catchwords. The English translation "phoenix man" may make the foreigners confused at first. An annotation can help eliminate the confusion. "The catchword is used to refer to a man, who was born and grew up in the country, finally live in the city with his own efforts”.

\subsubsection{Free Translation}

Free translation, a kind of translation method, means putting the content of original text in the first place instead of forms and emphasizing the information transmission. However, the translation method has a higher requirement for translators who should be familiar with the implication of the internet catchwords and make the inherent information conveyed in a proper way. Since most Chinese internet catchwords are culturally loaded which cannot be separated from social phenomena, free translation could only be applied into few translations.

Take "shanzhai" for example, the internet catchword has a totally fresh meaning different from its previous implication. "Copycatting" can be regarded as an equivalent expression of the catchword. Besides, the implication of copycatting is not strange for foreigners. Similar instances are: "shennv"- "woman left on the shelf"; "dajiangyou”- "It is none of my business. I’m just passing by"; "jiong” — “embarrassing”; "dai”—“stupid or silly".

\section{Conclusions}

With the increasing number of internet users, the internet has become part of our daily lives. Born and developed on the internet, the internet catchword plays a significant role in spreading the internet culture. Internet catchword, a particular language form, has been attracting increasing academic attentions at home and abroad.

Along with the rising position of China in the world and the tremendous contribution to the world, more and more foreigners pay attention to China and Chinese culture. The English translation of Chinese internet catchwords is urgent and necessary to transmit Chinese internet culture. Because of unique linguistic and cultural characteristics, the eco-translatology was adopted as the theoretical foundation to conduct the research. Under the guidance of the translation process and the translation method proposed by Hu Gengshen, the analysis is developed from two main aspects: adaptation and selection. Then, some possible translation methods are proposed to enrich the dissertation. It is hoped that the proposed translation methods could throw some lights on further studies in this area. Some innovations and implications have been achieved.

The implication of the article can be argued from two aspects: the theoretical and the practical aspect. First, as the theoretical foundation of the thesis, the eco-translatology is elaborated comprehensively including philosophical foundation, translational eco-environment, translators' adaptation and selection and three-dimensional transformations, which provides a more comprehensive approach to get acquainted with Hu's theory. The analy- 
sis of the English translation of Chinese internet catchwords is developed from two main aspects: adaptation and selection. Some Chinese internet catchwords and corresponding English translations are illustrated to enrich the discussion. Besides, four traditional translation methods and two innovative ones are put forward after the analysis. Another implication is the practical aspect.

The study of the English translation of Chinese internet catchwords can propagate the transmission of Chinese culture especially the internet culture and let more foreigners get acquainted with Chinese internet catchwords. Besides, some insights will be provided for further analysis of Chinese internet catchwords.

Although the analysis of English translation of Chinese internet catchwords is conducted comprehensively, it is not sufficient and tentative. Limitations still exist. In the following, the limitations of the article will be presented. First, because of the author's limited knowledge, time and energy and the length of the artical, the data in the thesis especially the corresponding English translation of Chinese internet catchwords are not comprehensive enough. Second, the possible translation methods proposed in the dissertation are not enough and perfect. Due to the particular linguistic, cultural and communicative features of Chinese internet catchwords, the translation methods proposed cannot be applied into all the discussions of the Chinese internet catchwords. Third, owing to the limited academic attainments, the dissertation needs to be deepened.

On the whole, the article is a bold attempt in the area of English translation of Chinese internet catchwords. The research will make some contributions to the transmission of Chinese internet catchwords and internet culture. More researches related to the English translation of Chinese internet catchwords are expected to be conducted in the future.

\section{References}

[1] David, C. (2006) Language and the Internet. Cambridge University Press, Cambridge.

[2] Liu, H.Y. (2002) Internet Language. China Radio \& Television Publishing House, Beijing.

[3] Hu, G.S. (2004) An Approach to Translation as Adaptation and Selection. Hubei Education Press, Wuhan.

[4] Wang, N. (2011) Eco-Literature and Eco-Translatology: Deconstruction and Reconstruction. Chinese Translators Journal, 2, 10-15.

[5] Hall, E.T. (1997) Beyond Culture. Anchor Books, New York.

[6] Hu, Z.L. (2008) The Course: Introduction to Linguistics. Peking University Press, Beijing. 
Scientific Research Publishing (SCIRP) is one of the largest Open Access journal publishers. It is currently publishing more than 200 open access, online, peer-reviewed journals covering a wide range of academic disciplines. SCIRP serves the worldwide academic communities and contributes to the progress and application of science with its publication.

Other selected journals from SCIRP are listed as below. Submit your manuscript to us via either submit@scirp.org or Online Submission Portal.
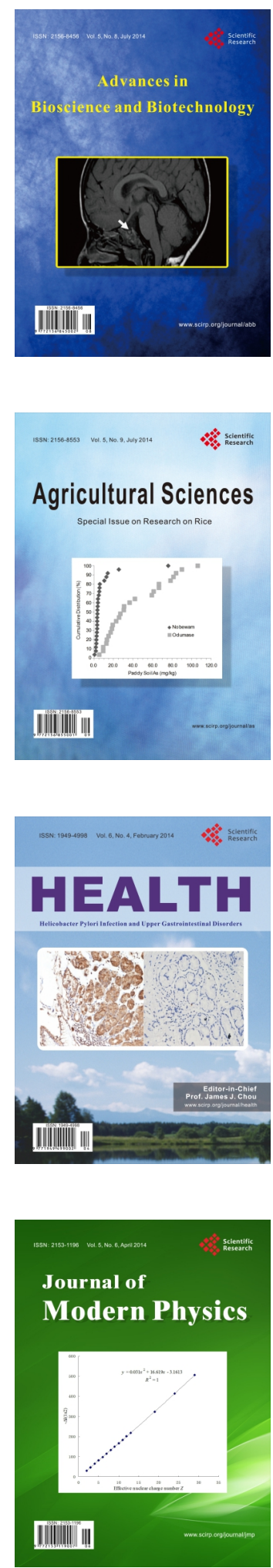
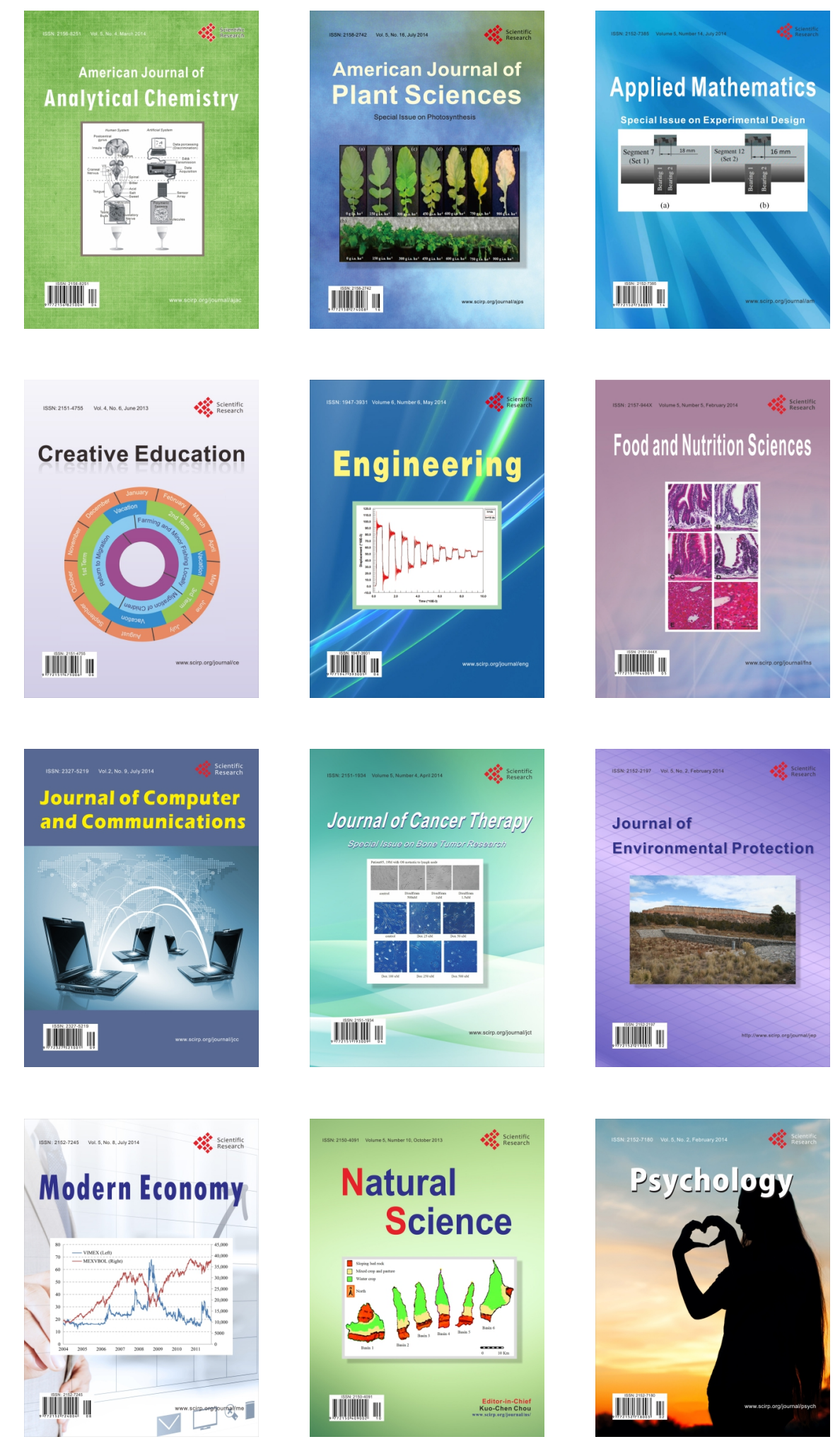